\title{
Edaravone Attenuates Impairment of Synaptic Plasticity in Granule Cell Layer of the Dentate Gyrus Following Traumatic Brain Injury
}

\author{
SHIN YAMASHITA***, HIROSHI HASUO*, TAKASHI TOKUTOMI**, \\ MINORU SHIGEMORI** AND TAKASHI AKASU*,† \\ Department of Physiology* and Neurosurgery**, Kurume University School of Medicine, and \\ ${ }^{+}$Cognitive and Molecular Research Institute of Brain Diseases, Open Research Center, \\ Kurume University, Kurume 830-0011, Japan
}

Received 28 December 2010, accepted 7 April 2011

\begin{abstract}
Summary: Effects of edaravone, a free radical scavenger, on post-traumatic impairment of long-term potentiation (LTP) were examined in granule cell layers of the dentate gyrus (DG) in vitro. Field EPSPs (fEPSPs) evoked by stimulation of the perforant path (PP) were recorded extracellularly in the DG one week after a moderate impact applied by a fluid percussion injury (FPI) device. High frequency stimulation (HFS) of the PP caused LTP of the fEPSP-slope in slices from naïve and sham-operated rats, however, the LTP was strongly depressed in slices from FPI rats. Intraperitoneal administration of edaravone $15 \mathrm{~min}$ after FPI prevented the hyperactivities of DG neurons and attenuated impairment of the LTP in FPI rat dentate granular cells. In vitro application of spermine NONOate (sp-NO), a nitric oxide (NO) donor, for 30 min produced a gradual increase in the fEPSPslope, lasting for more than $2 \mathrm{~h}$. Edaravone attenuated the enhancement of the fEPSP-slope induced by sp-NO. After sp-NO treatment HFS could not produce an obvious LTP in the DG granule cell layer. Pretreatment of DG slices with edaravone prevented the sp-NO-induced impairment of LTP. These results suggest that administration of edaravone after FPI protects against post-traumatic impairment of LTP in granule cell layers of the DG, possibly by scavenging NO-related radicals.
\end{abstract}

Key words traumatic brain injury, long-term potentiation, hyperactivity, dentate granule cells, edaravone, neuroprotection, nitric oxide, free radical scavenger

\section{INTRODUCTION}

The neurological consequences of traumatic brain injury (TBI) are memory disturbance, cognitive impairment and chronic seizures that are related to the dysfunction of the hippocampal formation after head injury [1-3]. Fluid percussion injury (FPI) of the rat brain is the most extensively used and well characterized animal model of human TBI [4-6]. It has been shown that mossy neurons in the dentate gyrus (DG) were most vulnerable to various forms of injury, including epilepsy, ischemia and traumatic head injury [7-9]. Facilitation in the DG lowered thresholds for developing self-sustained seizure activity 1-12 weeks post-injury compared to sham-operated animals $[9,10]$. Functional studies showed that posttraumatic hyperactivity occurred in neurons of the hippocampal CA1 and the DG in FPI rats [7,11,12]. In the rat hippocampal CA1 area, impairment of longterm potentiation (LTP), which is thought to be a cellular model of memory function [13,14], has been shown in both in vivo $[15,16]$ and in vitro prepara-

Correspondence to: Dr. Hiroshi Hasuo, Department of Physiology, Kurume University School of Medicine, 67 Asahi-machi, Kurume 830-0011, Japan. Tel: +81-942-31-7543 Fax: +81-942-31-7728 E-mail: hhasuo@med.kurume-u.ac.jp

Abbreviations: ACSF, artificial cerebrospinal fluid; CNS, central nervous system; DBCH, dormant basket cell hypothesis; DG, dentate gyrus; DL-APV, DL-2-

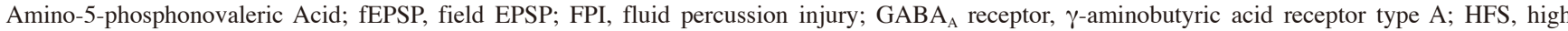
frequency stimulation; I-O curves, input-output relations; IPSP, inhibitory postsynaptic potential; Lt, left hemisphere; LTD, long-term depression; LTP, longterm potentiation; mPP, medial perforant path; NMDA, $n$-methyl-D-aspartate; NO, nitric oxide; $\cdot \mathrm{OH}$, hydroxyl radical; PP, perforant path; pSpike, population spike; PSPs, postsynaptic potentials; RNS, reactive nitrogen species; ROS, reactive oxygen species; Rt, right hemisphere; sp-NO, spermine NONOate; TBI, traumatic brain injury. 
tions [17-19]. Various molecular biological cascades have been reported to lead to cellular dysfunctions after TBI $[20,21]$. Nitric oxide (NO) not only mediates LTP and long-term depression (LTD) [22-24] but also causes direct neurotoxicity in central neurons $[25,26]$. Superoxide also has characteristic features, acting both as a functional messenger molecule for neuronal processes of LTP $[27,28]$ and as a neurotoxic molecule [29-31]. Reactive free radicals, including reactive oxygen species (ROS) and reactive nitrogen species (RNS), are also implicated in the pathogenesis of various brain injuries, such as TBI, ischemia, and neurodegenerative disorders [31,32]. Edaravone (3-methyl-1-phenyl-2-pyrazolin-5-one: MCI-186) is a novel free radical scavenger clinically used as a neuroprotective agent against acute cerebral ischemia $[33,34]$. Edaravone is also shown to inhibit postischemic increases in hydroxyl radical $(\cdot \mathrm{OH})$ production and tissue injury in the penumbral or recirculated area in rat cerebral ischemia models [35,36]. Melatonin and phenylbutylnitrone, free radical scavengers, had protective effects against TBI via scavenging ROS and RNS [37-39]. We investigated the effect of edaravone on neuronal activity and LTP in the granule cell layer of the rat DG following head trauma. Preliminary findings of this work have appeared earlier [12].

\section{MATERIALS AND METHODS}

\section{Surgical operation and FPI}

Adult male Wistar rats were used for the entire study and were divided into 4 groups: one naïve group $(\mathrm{n}=20)$, one sham-operated group $(\mathrm{n}=18)$, one receiving lateral FPI $(n=14)$, and one group receiving FPI with subsequent edaravone $(n=12)$. This study was carried out in accordance with Kurume University's Guide for Animal Experimentation. FPI of the rat brain was carried out by the methods described previously $[4,11,40]$. Rats $(230-260 \mathrm{~g}, \mathrm{n}=26)$ were subjected to FPI at a moderate severity (4.2 atm) under pentobarbital anesthesia $(50-60 \mathrm{mg} / \mathrm{kg}$, i.p.). Edaravone $(8 \mathrm{mg} /$ $\mathrm{kg}$ ) was administered trans-peritoneally $15 \mathrm{~min}$ after the FPI. The rat scalp was sagittally incised from bregma to lambda and a $3 \mathrm{~mm}$ hole was trephined in the skull at $-3 \mathrm{~mm}$ (i.e. caudal) from the bregma, and $3.5 \mathrm{~mm}$ left of the sagittal suture. A leure-loc syringe hub with a $2.6 \mathrm{~mm}$ inside diameter was introduced through the hole, taking care not to compress the brain surface, and was bonded to the skull with cyanoacrylate adhesive. The hub was filled with saline before it was connected to the fluid percussion device. The fluid percussion device (HPD-1700: Dragonfly R \& D, Inc., Ridgeley, WV, USA) consisted of a stainless steel cylinder with a $2.7 \mathrm{~cm}$ bore and a $7.6 \mathrm{~cm}$ piston stroke that was connected to the hub via high-pressure tubing. At the other end of the cylinder, a weighted pendulum arm was suspended a fixed distance above the head of the piston, which was sealed within the cylinder. Brain injury with moderate impact at a pressure of $4.2 \pm 0.1 \mathrm{~atm}$ was achieved by allowing the metal pendulum to strike the piston to inject a small volume of saline into the closed cranial cavity. The resulting pressure pulse was measured by a pressure transducer connected to a digital storage oscilloscope (DS-8608A, Iwatsu Test Instruments Co., Tokyo, Japan). The pH, $\mathrm{pCO}_{2}, \mathrm{PO}_{2}$ and $\mathrm{O}_{2}$ saturation in arterial blood were measured 20-30 min after impact with an $850 \mathrm{pH} /$ Blood Gas System (Bayer Medical Co., Ltd., Tokyo, Japan). The weights of rats before impact and 7 days later were not significantly different from those of naïve rats. No evidence of any behavioral seizure activity was seen 1-2 weeks after the FPI. Sham-operated rats were treated in the same way including connection to the FPI device, but the pendulum was not released.

\section{Brain slice preparations}

After a survival period of 1 week, the rats were deeply anaesthetized with pentobarbital sodium (50$65 \mathrm{mg} / \mathrm{kg}$, i.p.) and killed by decapitation for slice experiments. Horizontal brain sections $(400 \mu \mathrm{m}$ in thickness) were cut from the ventral-to-mid section at $-5.6--6.4 \mathrm{~mm}$ from bregma by a Vibroslice (Campden Instruments, Ltd., Loughborough, Leics., UK). The brain slices were left for $1 \mathrm{~h}$ to recover in oxygenated artificial cerebrospinal fluid (ACSF) at room temperature $\left(22-24^{\circ} \mathrm{C}\right)$. The composition of the ACSF was as follows (in $\mathrm{mM}$ ): $\mathrm{NaCl}, 117 ; \mathrm{KCl}, 4.7$; $\mathrm{CaCl}_{2}, 2.5 ; \mathrm{MgCl}_{2}, 1.2 ; \mathrm{NaHCO}_{3}, 25 ; \mathrm{NaHPO}_{4}, 1.2$ and D-glucose, 11 (299 $\pm 4 \mathrm{mOsm})$.

\section{Extracellular recording}

Brain slices were continuously perfused with oxygenated ACSF at $30-32^{\circ} \mathrm{C}$ containing picrotoxin (100 $\mu \mathrm{M})$, a $\mathrm{GABA}_{\mathrm{A}}$ receptor $(\gamma$-aminobutyric acid receptor type A) antagonist which blocks fast inhibitory postsynaptic potentials during recordings. Extracellular recordings were made from the DG granule cell layer with a glass microelectrode filled with $1 \mathrm{M} \mathrm{NaCl}(1-2$ $\mathrm{M} \Omega$ ) (Fig. 1A). A bipolar-stimulating electrode was placed on the medial perforant path (mPP) in the molecular layers of the DG. The intensity of the test stimulus was chosen to yield a population spike (pSpike) of field EPSP (fEPSP) that was half the size necessary 
A

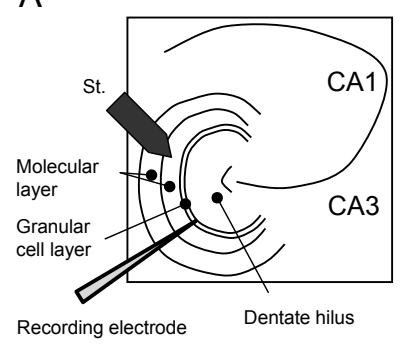

C a

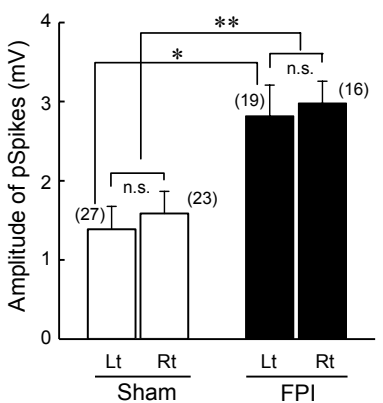

Fig. 1. Effects of FPI on the pSpike and fEPSP in the dentate granular cell layer. (A) Schematic diagram of horizontal section of the brain slice that includes the hippocampal formation and perforant path. Stimulus electrode was placed on the inner molecular layer of the DG (local stimulation) to stimulate the mPP. (B) Extracellular recordings of the field potentials in granule cell layer of the DG superfused with an ACSF containing picrotoxin $(100 \mu \mathrm{M})$. Left and right traces were obtained by stimulus intensities of $10 \mathrm{~V}$ from sham-operated and FPI rats, respectively. A triangle indicates the time of stimulation. (C) Pooled data for the pSpike evoked by stimulus intensities of $10 \mathrm{~V}$ (a) and the fEPSP slope evoked by stimulus intensities of $6 \mathrm{~V}$ (b) obtained from sham-operated (open columns) and FPI (closed columns) rats, respectively. Data were obtained from the ipsilateral $(\mathrm{Lt})$ and contralateral (Rt) hemispheres of the rat brain. Values are presented as mean \pm SEM. Vertical lines on each column represent SEM $(* \mathrm{p}<0.05, * * \mathrm{p}<0.01$, n.s.; no significance). The number of slices is shown in parentheses.

to activate the maximum response (7-10 V for $200 \mu \mathrm{s})$. Six consecutive postsynaptic potentials (PSPs) were averaged. To induce LTP, high frequency stimulations (HFS; $100 \mathrm{~Hz} 0.1 \mathrm{~s}$ applied 6 trains every $10 \mathrm{~s}$ ) were delivered at the necessary stimulus intensity to elicit a maximum response (usually $15-20 \mathrm{~V}$ for $200 \mu \mathrm{s}$ ). Evaluation of LTP was made at $30-50$ min post-HFS and was expressed as the ratio of either the pSpike amplitude or the initial slope of fEPSP to the respective baseline responses obtained $20 \mathrm{~min}$ before the HFS. We used the pClamp system (Axon Instruments,
Union city, CA, USA) operated by a computer (Dell, Round Rock, TX, USA) for data acquisition and later analysis.

\section{Statistical analysis}

Experimental data from different slices were pooled and presented as the mean \pm SEM (standard error of the mean). Differences between experimental and control values were tested using the unpaired Student's $t$-test; $\mathrm{p}<0.05$ was accepted as statistically significant. Comparison of groups (more than three) were assessed by the one-way or two-way analysis of variance (ANOVA), followed by post-hoc test (the Dunn's method or the Holm-Sidak method) for multiple pairwise comparisons using SigmaPlot 11 software (Systat software, Inc., San Jose, CA, USA); $<<0.05$ was accepted as statistically significant.

\section{RESULTS}

Effects of FPI on neuronal excitability in the dentate granule cell layer

Extracellular field recordings in the dentate granule cell layer showed a somatic fEPSP associated with a pSpike following stimulation of the mPP (Fig. 1B). The minimal stimulus intensity needed to evoke visible fEPSPs (threshold) was obtained from the normal control (naïve) rats and sham-operated rats. The threshold for elicitation of the fEPSP was $2.0 \pm 0.1 \mathrm{~V}$ $(\mathrm{n}=16$ slices) in 8 naïve rats and $2.1 \pm 0.1 \mathrm{~V}(\mathrm{n}=18$ slices) in 9 sham-operated rats. Similarly, the stimulation intensity that produced the minimum fEPSP was $2.1 \pm 0.2 \mathrm{~V}(\mathrm{n}=32)$ in 14 FPI rats. These results suggest that there is no statistical difference in the threshold for fEPSP in naïve, sham-operated and FPI rats. In contrast, the amplitude of the pSpike in dentate granule cell layers in FPI rats was significantly enhanced compared with those in naïve and sham-operated rats (Fig. 1B). The pSpike amplitude evoked by a stimulus intensity of $10 \mathrm{~V}$ was $1.4 \pm 0.3 \mathrm{mV}$ ( $\mathrm{n}=27$ slices) in sham-operated rats and $2.8 \pm 0.4 \mathrm{mV}(\mathrm{n}=19$ slices $)$ in FPI rats (Fig. 1C). The initial slope of the fEPSP evoked by a stimulus intensity of $6 \mathrm{~V}$ was $0.40 \pm 0.05$ $\mathrm{mV} / \mathrm{ms}(\mathrm{n}=23)$ in sham-operated rats and $0.68 \pm 0.06$ $\mathrm{mV} / \mathrm{ms}(\mathrm{n}=15)$ in slices from post-FPI rats. These differences were statistically significant $(p<0.05)$. However, there was no significant difference in the amplitude of pSpike or the slope of the fEPSP between ipsilateral (left hemisphere; Lt) and contra-lateral (right hemisphere; Rt) dentate granule cell layers in either sham-operated or FPI rats. These data suggest that, under present experimental conditions, the effect 
of the FPI on the excitatory synaptic transmission occurs bilaterally in the FPI rat DG. Therefore, comparisons between the values obtained from sham and FPI groups were made using pooled data from both $\mathrm{Lt}$ and Rt. The differences in both the amplitude of pSpike and the slope of fEPSP (Fig. 1C) were statistically significant $(\mathrm{p}<0.01)$.

\section{Effect of FPI on LTP in the dentate granule cell layer}

The time course and the magnitude of LTP in the dentate granule cell layer were determined in naïve, sham-operated and FPI rats. DG slices from each group were superfused with an ACSF containing picrotoxin $(100 \mu \mathrm{M})$ to block $\mathrm{GABA}_{\mathrm{A}}$ receptors. When the HFS (6 trains of 10 pulses with frequency of $100 \mathrm{~Hz}$ every $10 \mathrm{~s}$ ) was applied to the $\mathrm{mPP}$, the pSpike amplitude of dentate granule cells gradually increased after tetanization over a period up to $8 \mathrm{~min}$ and then plateaued.

The enhancement of the amplitude lasted for more than $2 \mathrm{~h}$, forming LTP in the sham-operated group (Fig. 2A). In these experiments, the average amplitudes of 60 consecutive pSpikes (10 min) were obtained before and 30 min after HFS. After delivery of the HFS to the mPP, the pSpike increased in amplitude to $270 \%$ of the control (before HFS) in shamoperated rats. The HFS-induced LTP in the DG was blocked by DL-2-Amino-5-phosphonovaleric Acid (DL-APV; $50 \mu \mathrm{M}$ ), a selective $n$-methyl-D-aspartate (NMDA) receptor antagonist (data not shown). Since previous studies have suggested that FPI erases the synaptic mechanisms required for LTP induction $[15,16]$, LTP was compared between sham-operated and FPI rat groups. When HFS was applied to the mPP, a potentiation of the $\mathrm{pSpike}$ amplitude was seen in FPI rats. The average amplitude of 60 consecutive pSpikes obtained 30 min after HFS was approximately $150 \%$ of the control (before HFS). Figure 2B shows pooled data for LTP of the pSpike amplitude obtained $30 \mathrm{~min}$ after HFS in 9-14 slices. The magnitude of LTP was compared between naïve and sham-operated rats. HFS increased the amplitudes of pSpike to $272 \pm 26 \%$ ( $\mathrm{n}=10$ slices, Lt) and $254 \pm 16 \%$ ( $\mathrm{n}=11$ slices, Rt) of the control in the sham group, and $252 \pm 12 \%$ ( $\mathrm{n}=9$ slices, $\mathrm{Lt}$ ) and $261 \pm 35 \%$ ( $n=10$ slices, Rt) of the control in the naïve group (Fig. 2B). Thus, there was no significant difference in percent increase in the amplitude of pSpikes in the DG between sham-operated and naïve rats. These results suggest that sham-operation caused no significant depression of LTP in the dentate granule cell layer of the DG. In contrast, the amplitude of the pSpike was only $153 \pm 6 \%(n=14, \mathrm{Lt})$ and $151 \pm 13 \%$
A
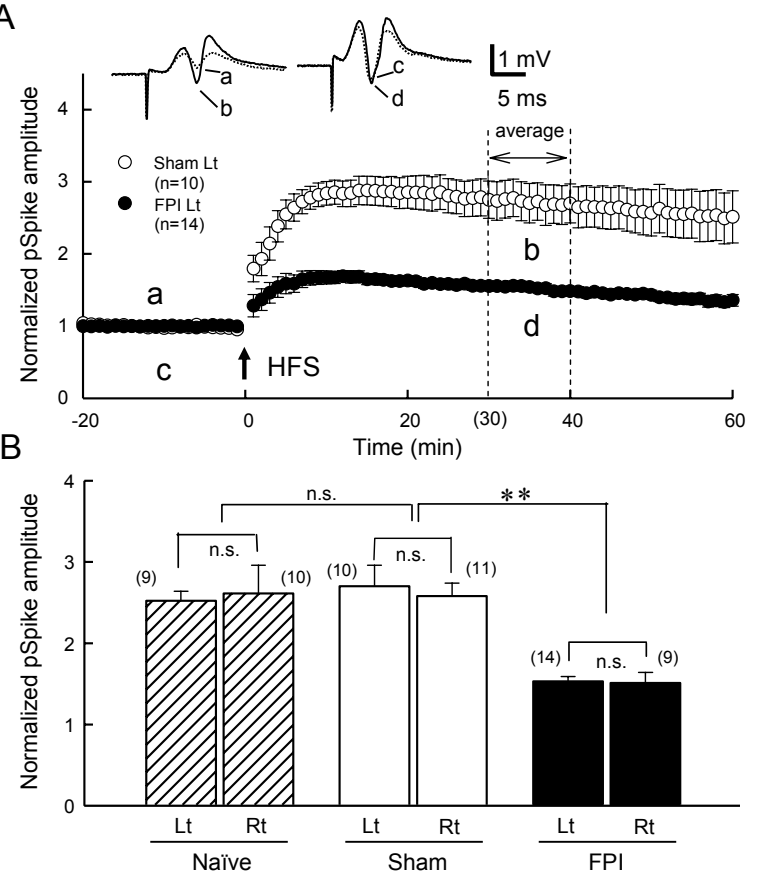

Fig. 2. Effects of FPI on the LTP in DG. (A) Time course of LTP of the pSpike amplitude in dentate granule cell layer obtained from sham-operated (open circles) and FPI (closed circles) rats. Upward arrow indicates the time for HFS of the mPP. Each symbol depicts the average amplitude of pSpike. Records (a-d) in insets were representative traces obtained at the time indicated by respective letters in the lower graph. All data were obtained from ipsilateral $(\mathrm{Lt})$ hippocampal neurons. Vertical lines on each data point represent SEM. (B) Pooled data for LTP in ipsilateral (Lt) and contralateral (Rt) dentate granule cell layers in naïve (oblique columns), shamoperated (open columns) and FPI (closed columns) rats. The amplitude of pSpike was averaged between 30 and 40 min after the HFS. Values are presented as mean \pm SEM. Vertical lines on each column represent SEM $(* * \mathrm{p}<0.01$, n.s.; no significance). The number of slices is shown in parentheses.

$(\mathrm{n}=9, \mathrm{Rt})$ of the control in FPI rats. The percent increase in pSpike amplitude in FPI rats was smaller than that obtained from the sham-operated rat group (sham vs. FPI, $\mathrm{p}<0.01)$. Furthermore, LTP of the pSpike amplitude was similar in both Lt and Rt in FPI animals. These results suggest that fluid percussion causes functional disturbance of excitatory synapses that mediate the induction and maintenance of LTP in the dentate granule cell layer.

FPI produced a similar effect on LTP of the fEPSP slope in dentate granule cell layers. Figure 3A shows time courses of LTP determined by the fEPSP slopes in sham-operated and FPI rats. In this study, HFS 
increased the slope of 60 consecutive fEPSPs to $150 \%$ $(\mathrm{Lt})$ of control in sham-operated rats and $118 \%(\mathrm{Lt})$ of control in FPI rats (Fig. 3A). Pooled data from 10 slices in 5 rats showed that sham-operated rats responded to the HFS of the $\mathrm{mPP}$ with a long-lasting potentiation of the fEPSP slope by $141 \pm 7 \%$ (Lt) and $140 \pm 9 \%$ (Rt) of control (Fig. 3B). Percent increases in the fEPSP slope were $109 \pm 3 \%$ (Lt) of control and $104 \pm 7 \%$ (Rt) of control in 8-13 slices from 6 FPI rats. There was no difference between Lt and Rt in the DG.

A

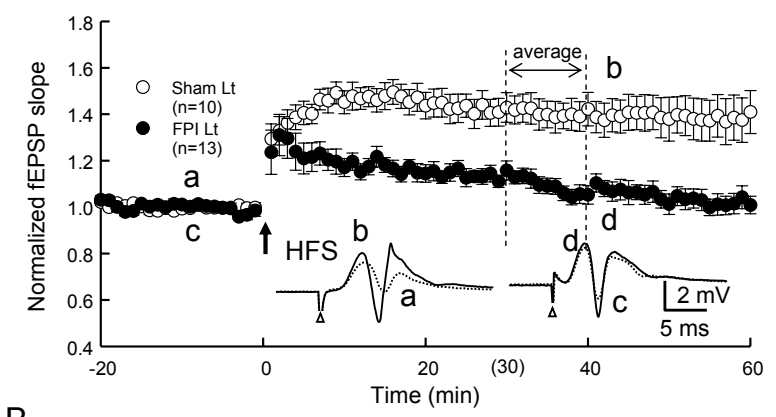

B

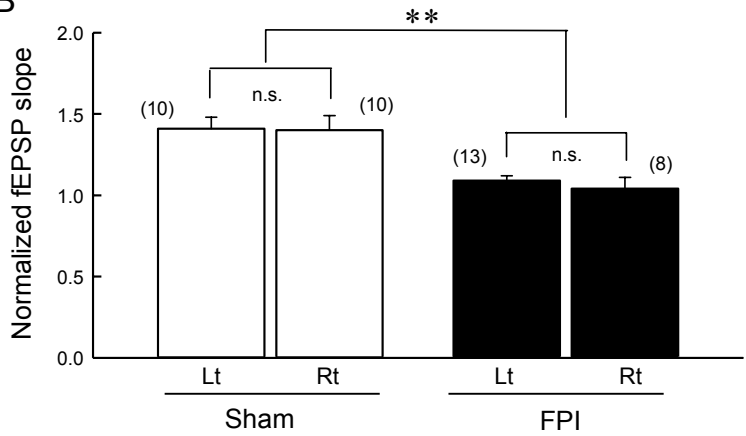

Fig. 3. LTP of fEPSP-slope taken in the dentate granular cell layer of sham-operated and FPI rats. DG slices were superfused with an ACSF containing picrotoxin $(100 \mu \mathrm{M})$. (A) fEPSPs were evoked by single stimulation with an intensity of 6-9 V. Open and closed circles were obtained from sham-operated $(n=10)$ and FPI $(n=13)$ rats, respectively. The upward arrow indicated the time of HFS. Insets show sample records of the fEPSP obtained before and $40 \mathrm{~min}$ after HFS in sham (left traces) and FPI (right traces) groups, respectively. Records (a-d) were obtained at the times indicated by respective letters in the graph. (B) Pooled data for LTP of the fEPSP slope of ipsilateral (Lt) and contralateral (Rt) dentate granule cell layers in sham-operated and FPI rats. Each column indicates average value of normalized fEPSP slopes obtained between 30 and 40 min after HFS. Open and closed columns were obtained from shamoperated and FPI rats, respectively. Vertical lines on each column represent SEM $(* * \mathrm{p}<0.01$, n.s.; no significance). The number of slices is shown in parentheses.
Pooled data showed a significant difference between the values obtained from sham and FPI groups $(p<0.01)$. These results suggest that at one week after FPI, the HFS could not generate LTP, as determined by the fEPSP slope in dentate granule cell layers.

\section{Effect of edaravone on neuronal activity in dentate granule cells}

The post-traumatic hyperexcitability of synaptic transmission was examined in FPI rats with i.p. administration of edaravone $(8 \mathrm{mg} / \mathrm{kg})$, a free radical scavenger, 15 min after FPI. The rectal temperature of FPI rats was not significantly altered $\left(37.4 \pm 0.2^{\circ} \mathrm{C}, \mathrm{n}=7\right)$ after the administrations of edaravone. As a control study, we examined the effect of i.p. administration of edaravone on the neuronal activity in sham-operated rats. The pSpike amplitude in sham-operated rats showed no obvious changes 1 week after the administration of edaravone $(8 \mathrm{mg} / \mathrm{kg}$, i.p.) or saline (as vehicle) in dentate granule cells (data not shown). Figure 4A shows sample records of the field potentials elicited by stimuli of $\mathrm{mPP}$ with intensities between 1 to 10 $\mathrm{V}$ in sham-operated rats, FPI rats, and those with i.p. administration of edaravone. The fEPSP slopes $(\mathrm{mV} /$ $\mathrm{ms}$ ) were plotted against the intensity of stimuli (Vi) in sham-operated, FPI alone, and FPI rats treated with edaravone (Fig. 4B). The slope of the input-output relation (I-O curve) was evaluated individually by a linear regression program using the values obtained by the stimuli between 3 and $6 \mathrm{Vi}$, since the I-O curves showed high linearities at these range of stimuli. These I-O curves in ipsi- and contra-lateral dentate granular cell layers of sham-operated groups had slopes of $0.08 \pm 0.01 \mathrm{mV} / \mathrm{ms}$ vs. $\mathrm{Vi}(\mathrm{n}=23, \mathrm{Lt})$ and $0.10 \pm 0.01$ $\mathrm{mV} / \mathrm{ms}$ vs. $\mathrm{Vi}(\mathrm{n}=21, \mathrm{Rt})$, respectively. In contrast, the slopes of the I-O curve for the FPI alone groups were increased to $0.19 \pm 0.02 \mathrm{mV} / \mathrm{ms}$ vs. $\mathrm{Vi}(\mathrm{n}=11, \mathrm{Lt})$ and $0.17 \pm 0.02 \mathrm{mV} / \mathrm{ms}$ vs. Vi ( $\mathrm{n}=9, \mathrm{Rt})$. In FPI rats after i.p. administration of edaravone, however, the slopes of the I-O curve of the fEPSP recovered to $0.10 \pm 0.01$ $\mathrm{mV} / \mathrm{ms}$ vs. $\mathrm{Vi}(\mathrm{n}=13, \mathrm{Lt})$ and $0.08 \pm 0.01 \mathrm{mV} / \mathrm{ms}$ vs. Vi $(\mathrm{n}=8, \mathrm{Rt})$. Comparisons of the I-O curves were made using the 1-10 Vi data by two-way ANOVA. The values of the I-O curve for the FPI groups were significantly greater than those for the sham-operated group $(\mathrm{p}<0.01)$, indicating that FPI causes post-traumatic hyperexcitability of dentate granule cells. There was no statistical difference in the I-O curves between Rt and Lt. The I-O curves in FPI rats treated with edaravone were almost identical to those of sham-operated rats (Fig. 4B). Thus, i.p. administration of edaravone prevented the development of post-traumatic hyperexcitability of DG neurons. 


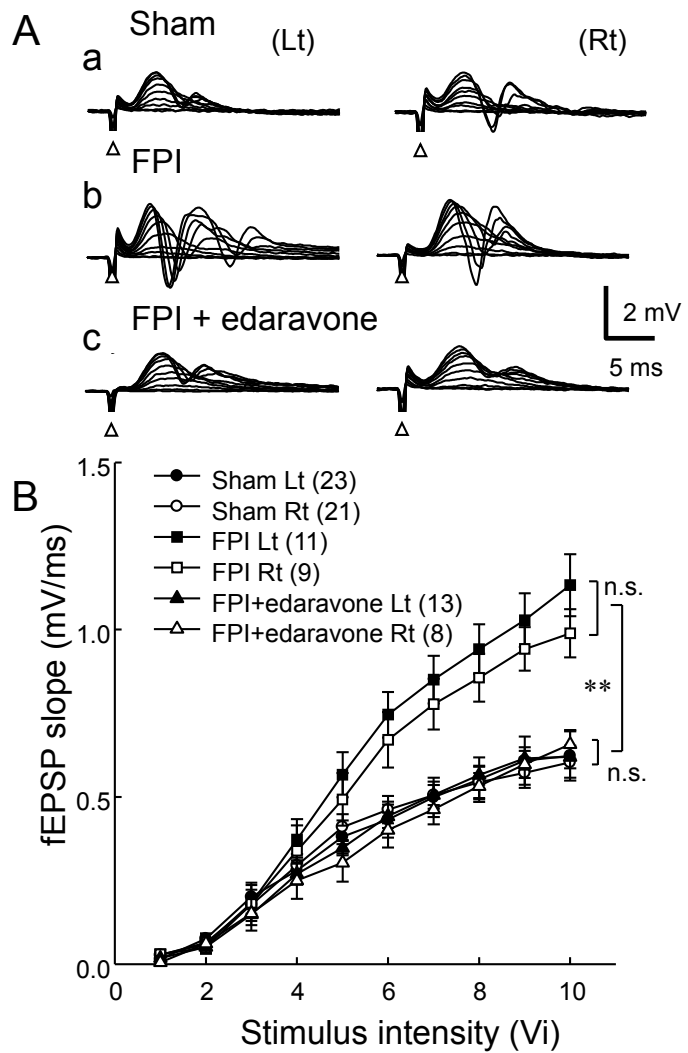

Fig. 4. Effects of edaravone on the hyperexcitability of dentate neurons after FPI. (A) The representative traces of field potentials which were obtained from sham-operated (a), FPI alone (b) and FPI with edaravone (c) rats. Intensity of stimuli was increased from $1 \mathrm{~V}$ to $10 \mathrm{~V}$ in $1 \mathrm{~V}$ increments. Left and right traces were obtained from $\mathrm{Lt}$ and $\mathrm{Rt}$, respectively. (B) Graph shows the relationship between the initial slope of fEPSPs $(\mathrm{mV} / \mathrm{ms})$ and the intensity of stimulations (Vi) in the granule cell layer in the DG. The fEPSP was evoked by stimulation of the mPP with intensities of 1-10 V. Circles, squares and triangles were obtained from shamoperated, FPI and FPI rats with i.p. administration of edaravone, respectively. Closed and open symbols were taken from Lt and Rt, respectively. Values are presented as mean \pm SEM. Vertical lines on each data point represent SEM $(* * \mathrm{p}<0.01$, n.s.; no significance, two-way ANOVA). The number of slices is shown in parentheses.

\section{Effects of edaravone on LTP in dentate granule cell layers}

LTP profiles were compared in FPI rats and those with i.p. administration of edaravone. In these experiments, brain slices were treated with picrotoxin (100 $\mu \mathrm{M})$ to block $\mathrm{GABA}_{\mathrm{A}}$ receptors. Figure $5 \mathrm{~A}$ shows the time courses of LTP of the fEPSP slope in FPI rats and

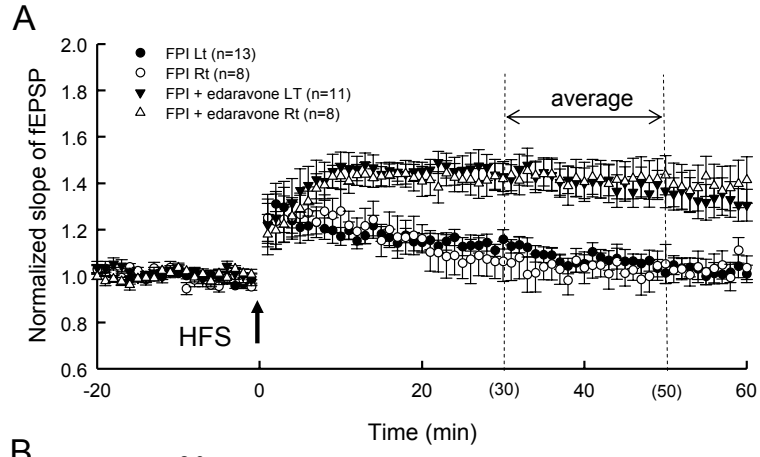

B

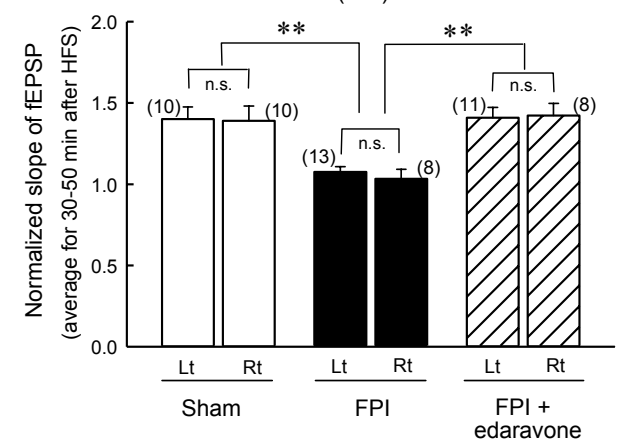

Fig. 5. Effects of i.p. administration of edaravone on the LTP of fEPSP in DG neurons. (A) Time course of the LTPs obtained from FPI alone (circles) and FPI rats with application of edaravone (triangles). Closed and open symbols were obtained from Lt and Rt hemisphere of rat brain, respectively. The number of slices is shown in parentheses. (B) Pooled data for the effect of i.p. administration of edaravone on the LTP. Open and closed and oblique columns were taken from sham-operated, FPI alone and FPI with edaravone groups, respectively. Right and left columns of each pair were obtained from right (Rt) and left (Lt) hemisphere of rat brain, respectively. Vertical lines on each column represent SEM $(* * \mathrm{p}<0.01, \mathrm{n} . \mathrm{s}$; no significance).

FPI rats with edaravone treatment. In the FPI alone group, the slope of fEPSPs returned to the baseline control level within 60 min after the HFS. However, the slope of fEPSP was still enhanced at $60 \mathrm{~min}$ after the HFS in FPI rats after i.p. administration of edaravone. Figure 5B shows pooled data for the effect of edaravone on the LTP determined by fEPSP slope, obtained 30-50 min after the HFS, in ipsi- and contralateral dentate granule cell layers. The magnitude of LTP was $140 \pm 7 \%(n=10, \mathrm{Lt})$ of control in sham-operated, $108 \pm 3 \%(\mathrm{n}=13, \mathrm{Lt})$ of control in FPI only, and $141 \pm 6 \%(\mathrm{n}=11, \mathrm{Lt})$ of control in FPI followed by edaravone treatment. The fEPSP slopes in contra-lateral dentate granular neurons were $139 \pm 9 \%(n=10$, $\mathrm{Rt})$ in sham-operated rats, $103 \pm 6 \%(\mathrm{n}=8, \mathrm{Rt})$ in FPI rats and $142 \pm 8 \%(\mathrm{n}=8, \mathrm{Rt})$ in FPI rats with edaravone 
(Fig. 5B). Pooled data showed a significant difference between the values obtained from the FPI-alone group and the FPI-treated with edaravone group. The edaravone treated group showed an LTP profile that was almost identical to that of the sham-operated group. These results suggest that i.p. administration of edaravone 15 min after FPI improves the post-traumatic impairment of LTP in the granule cell layer of the DG.

Effects of bath-application of spermine NONOate (sp$N O)$ and edaravone on the fEPSPs in the dentate granular cell layers

It has been shown that NO not only promotes or mediates LTP and/or LTD [22] but also causes direct neurotoxicity in central neurons $[25,26]$. It is important to know whether NO is related to the post-traumatic neuronal hyperexcitability and impairment of LTP in DG neurons. In addition, it has been reported that edaravone scavenges $\mathrm{NO}$ [41]. We examined the acute effects of NO donor and free radical scavenger on the fEPSP slope in dentate granule cells of naïve rats. Figure 6A shows the effect of bath-application of sp-NO, a NO donor, on the fEPSP slope in the dentate granular cell layer of naïve rats. Bath-application of sp-NO $(100 \mu \mathrm{M})$ for $30 \mathrm{~min}$ increased the initial slope of the fEPSP in the absence of edaravone $(100 \mu \mathrm{M})$ (Fig. 6A, open circles). In these experiments, the I-O curves of fEPSP were examined. Figure 6B shows the data obtained before and $50 \mathrm{~min}$ after application of sp-NO. After treatment of sp-NO, the normalized slope of fEPSP at $10 \mathrm{~V}$ stimulus increased to $1.51 \pm 0.20$ $(n=8)$. The I-O curve obtained after sp-NO treatment was significantly different from the control $(\mathrm{p}<0.05)$. The enhancement of the fEPSP slope developed within $60 \mathrm{~min}$ and was maintained for more than $120 \mathrm{~min}$ even after removal of sp-NO from the external solution. Pooled data showed that sp-NO $(100 \mu \mathrm{M})$ enhanced the fEPSP slope to $135 \pm 9 \%$ ( $n=9$ slices) of control (Fig. 6C, open column). These results suggest that sp-NO produces a long-lasting enhancement of the fEPSP slope in the dentate granule cell layer. The effect of sp-NO $(100 \mu \mathrm{M})$ on the fEPSP slope was also examined in the presence of edaravone $(100 \mu \mathrm{M})$ in the dentate granule cell layer (Fig. 6A). Brain slices were first superfused with an external solution containing edaravone $(100 \mu \mathrm{M})$ for $20 \mathrm{~min}$, and then sp-NO $(100 \mu \mathrm{M})$ was added to the edaravone $(100$ $\mu \mathrm{M}$ )-containing ACSF for $30 \mathrm{~min}$. Bath-application of edaravone itself produced no obvious change in the slope of fEPSP. Application of sp-NO $(100 \mu \mathrm{M})$ for 30 min did not consistently produce enhancement of the
fEPSP slope in the presence of edaravone $(100 \mu \mathrm{M})$ (Fig. 6A, closed circles). Pooled data showed that the fEPSP slope was $102 \pm 3 \%(n=5)$ of control in DG slices treated with both edaravone $(100 \mu \mathrm{M})$ and sp-NO $(100 \mu \mathrm{M})($ Fig. $6 \mathrm{C}$, closed column). This value
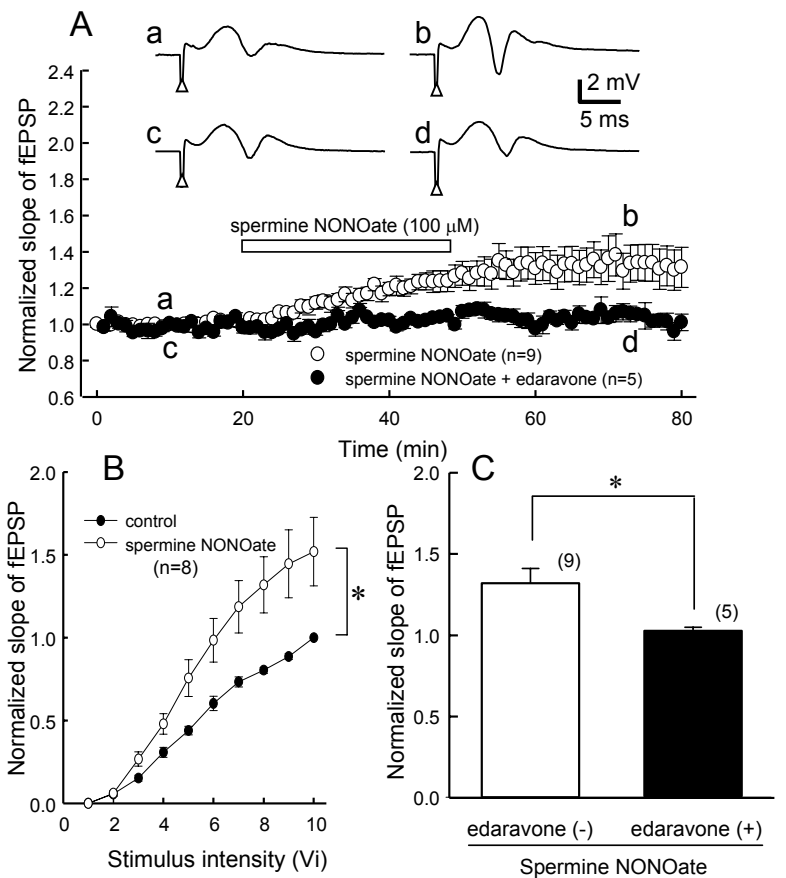

Fig. 6. Effect of in vitro administration of sp-NO and edaravone on the slope of fEPSPs. Experiments were done using DG slices of naïve rats. (A) Time course of the facilitation in the slope of fEPSP induced by bath-application of sp-NO $(100 \mu \mathrm{M})$. Circles indicate the average value of normalized slope of fEPSPs. Open and closed circles were obtained in the absence or in the presence of edaravone $(100 \mu \mathrm{M})$, respectively. Open horizontal bar indicates the period of the application of sp-NO $(100 \mu \mathrm{M})$ to the ACSF. The slope of fEPSP obtained before application of sp-NO was indicated as 1 . Sp-NO $(100 \mu \mathrm{M})$ was added to an ACSF containing edaravone $(100 \mu \mathrm{M})$. Records (a-d) in insets were representative traces obtained at the time indicated by respective letters in lower graph. (B) Pooled data for the input-output relations of the normalized slope of fEPSP before (closed circles) and after treatment of sp-NO (open circles). The slope of fEPSP at 10 $\mathrm{V}$ stimulus was indicated as 1 . Vertical lines on each symbol represent SEM $(* \mathrm{p}<0.05$, two-way ANOVA) (C) Pooled data for the effect of sp-NO $(100 \mu \mathrm{M})$ on the slope of fEPSP. Open and closed columns were taken in the absence and the presence of edaravone $(100 \mu \mathrm{M})$, respectively. The slope of fEPSP obtained before application of drugs was indicated as 1. Vertical lines on each column represent SEM $(* p<0.05)$. The number of slices is shown in parentheses. 
was significantly different from that obtained in the absence of edaravone (Fig. $6 \mathrm{C}, \mathrm{p}<0.05$ ). These results suggest that edaravone attenuates the NO-induced enhancement of fEPSP slope in the dentate granular cell layer.

\section{Effects of in vitro administration of edaravone and $s p-N O$ on LTP in dentate granule cell layers}

Brain slices were superfused with an ACSF containing picrotoxin $(100 \mu \mathrm{M})$ to block fast IPSPs. Application of HFS to the MPP produced a long-lasting enhancement of the fEPSP slope for more than $2 \mathrm{~h}$, producing typical LTP in naïve rats (data not shown). Pooled data showed that the magnitude of LTP in the fEPSP slope was $141 \pm 6 \%$ ( $n=11$ slices) of control in 6 naïve rats (Fig. 7B). Figure 7A shows the effects of pre-treatment of sp-NO $(100 \mu \mathrm{M})$ alone (open circles) and sp-NO $(100 \mu \mathrm{M})$ with edaravone $(100 \mu \mathrm{M})$ (closed circles) for $30 \mathrm{~min}$ on LTP in dentate granular cell layers. After treatment with sp-NO $(100 \mu \mathrm{M})$ alone, the HFS produced a transient decrease in the fEPSP slope ( $70 \%$ of control, $n=9$ ) that recovered within 10 min and then repotentiated (122\% of control, $n=9)$. However, the slope of fEPSP returned to the baseline level (before HFS level) within 60 min. Pooled data showed that the slope of the fEPSP obtained 40-50 min after HFS was $106 \pm 3 \%(\mathrm{n}=9)$ of the control in the presence of sp-NO (100 $\mu \mathrm{M})$ (Fig. 7B, oblique column). These results suggest that NO production by sp-NO $(100 \mu \mathrm{M})$ suppresses induction of LTP in dentate granule cell layers. The effect of sp-NO $(100 \mu \mathrm{M})$ on LTP was also examined in the presence of edaravone $(100 \mu \mathrm{M})$ in dentate granule cell layers. Application of edaravone $(100 \mu \mathrm{M})$ to the external solution for 30 min produced no effect on the fEPSP slope in granule cell layers. Sp-NO $(100 \mu \mathrm{M})$ was then added to edaravone-containing external solution. In the presence of both edaravone $(100 \mu \mathrm{M})$ and sp-NO $(100 \mu \mathrm{M})$, HFS of the perforant path enhanced the fEPSP slope to $150 \%$ of the control 40-50 min after HFS, producing LTP (Fig. 7A closed circles). Figure 7B (closed column) shows pooled data for the effect of in vitro application of both edaravone $(100 \mu \mathrm{M})$ and sp-NO $(100 \mu \mathrm{M})$ on LTP of fEPSP slope. Under these experimental conditions, the magnitude of LTP of fEPSP slope was $154 \pm 12 \%$ ( $n=5$ slices), which was significantly different from the value after sp-NO treatment alone. The effect of bath-application of edaravone alone on the HFS-induced LTP was investigated. The magnitudes of the LTP in the presence of edaravone $(100 \mu \mathrm{M}$ or $500 \mu \mathrm{M})$ were $133 \pm 10 \%(\mathrm{n}=7)$ for $100 \mu \mathrm{M}$ and $112 \pm 5 \%(\mathrm{n}=4)$ for $500 \mu \mathrm{M}$, respec-
A
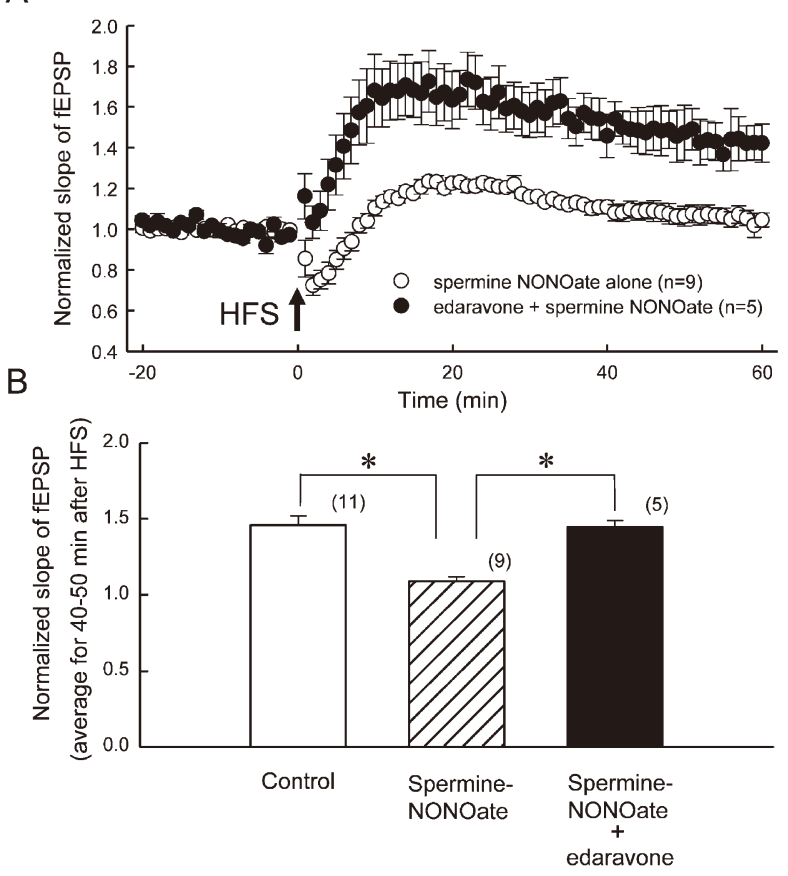

Fig. 7. Effect of in vitro administration of sp-NO on the LTP of fEPSP in granular neurons of DG. (A) Time course of the fEPSP slope obtained before and after application of the HFS to the perforant path. Experiments were done using DG slices of naïve rats. Open and closed circles indicate the data obtained in the presence of sp-NO $(100 \mu \mathrm{M})$ alone and in the presence of both edaravone $(100 \mu \mathrm{M})$ and sp-NO $(100 \mu \mathrm{M})$, respectively. The time of the HFS is indicated by an upward arrow. The mean slope of fEPSP obtained before application of HFS was indicated as 1 . Values are presented as mean \pm SEM. (B) Pooled data for the magnitudes of LTP obtained from control slices, sp-NO $(100 \mu \mathrm{M})$ alone treated slices, and both edaravone $(100 \mu \mathrm{M})$ and sp-NO $(100 \mu \mathrm{M})$ treated slices, respectively. Vertical lines on column represent SEM $(* \mathrm{p}<0.05)$. The number of slices is shown in parentheses.

tively (data not shown). The value for edaravone (500 $\mu \mathrm{M})$ was significantly different from the control value. These results suggest that edaravone attenuates the spNO-induced depression of LTP, probably by blocking NO-dependent processes of induction and maintenance of LTP in the granule cell layer of the DG. These results indicate that i.p. administration of edaravone at an early period after FPI may be effective in preventing post-traumatic impairment of LTP.

\section{DISCUSSION}

The present study showed that 1) FPI enhanced 
the fEPSP slope and the pSpike amplitude, 2) FPI suppressed the induction and maintenance of LTP in the fEPSP and the pSpike, and 3) i.p. administration of edaravone in the early post-traumatic period (15 min after the FPI) prevented the hyperactivity of neurons and the impairment of LTP in bilateral dentate granule cell layers. The enhancement of the fEPSP slope and the pSpike amplitude following FPI was associated with no obvious change in the threshold for their generation in the granule cell layer of the DG. The slope of the I-O curve was increased in FPI rats as compared with sham-operated rats. These results suggest that the efficacy of excitatory synaptic transmission is enhanced in the dentate granule cell layer after FPI. FPI has been shown to enhance the excitatory synaptic function in hippocampal CA1 neurons of FPI rats $[11,40]$. As regards the mechanism of post-traumatic hyperexcitability, several hypotheses have appeared in regard to the DG. Santhakumar et al. [42] have reported an 'irritable mossy cells hypothesis' in DG neurons. Increased discharge of granule cells driven by a hyperexcitable feedback pathway from mossy hilar cells results in the development of post-traumatic seizures and memory deficits. Surviving mossy hilar cells mainly contribute to the hyperexcitability of dentate granule cells after the FPI. Sloviter $[43,44]$ proposed a 'dormant basket cell hypothesis $(\mathrm{DBCH})$ ' that described the importance of mossy cell degeneration in the DG. Persistent increase in glutamate release from the perforant path leads to a decrease in the excitation of inhibitory interneurons, resulting in the disinhibition of excitatory granule cells. In connection to the hyperexcitability of mossy hilar cells after head trauma, mossy fiber synaptic reorganization has been demonstrated in human temporal-lobe epilepsy [45]. This plasticity includes an early and persistent abnormal sprouting of granule cell axons (mossy fibers) synapsing in the molecular layer $[46,47]$. Our previous study has suggested that the post-traumatic hyperexcitability in the hippocampal CAl neurons is caused at least in part by the facilitation of glutamatergic transmission [11]. The results in the present study also suggest that FPI causes hyperactivity of excitatory synaptic transmission in rat dentate granular cell layers lasting at least 1 week after FPI.

LTP, a long-lasting synaptic plasticity, is the experimental paradigm of the cellular basis for learning and memory $[13,14,48]$. A previous study showed that the enhancement of inhibitory synaptic activity reduced hyperexcitability in hippocampal CA1 neurons in FPI rats [40]. The depression of LTP in dentate granule cell layers was not related to the disinhibition after FPI, because DG slices were superfused with an ACSF containing picrotoxin, an inhibitor for $\mathrm{GABA}_{\mathrm{A}}$ receptors. One of the most interesting findings of the present study was the co-existence of the impairment of LTP and the enhancement of the fEPSP in the dentate granule cell layer following FPI. It has been proposed that one of the likely mechanisms for the lack of induction of LTP is probably LTP itself, because pathways previously enhanced by FPI, a pathological form of LTP, cannot endure successive LTP $[18,49]$. It has been known that the NMDA receptor-dependent pathway is closely related to injury-induced LTP impairment in mouse hippocampal CA1 after TBI [21]. The initial response to brain injury is an indiscriminant recurrent release of excitatory neurotransmitters, leading to widespread depolarization [50-52] that consequently releases the voltage-sensitive magnesium block of the NMDA receptors [53]. Moreover, Zhang et al. [54] have demonstrated relief from magnesium block of the NMDA receptors following mechanical injury to cortical neurons. The large and sudden increase in extracellular glutamate after a brain injury would result in an increase in $\mathrm{Ca}^{2+}$ influx to the intracellular space, leading to pathologic LTP. The hyperactivity of excitatory synaptic transmission may occlude subsequent LTP induction in dentate granule cell layers.

Various molecular biological cascades have been reported to be involved in the process of the induction and maintenance of LTP after TBI [20,21]. NO not only acts as a direct neurotoxic molecule $[25,26]$, but also promotes or mediates LTP or LTD [22-24]. ROS, including superoxide, also exhibit two opposite features, such as neurotoxity [31], while also functioning as messenger molecules in neuronal processes of synaptic plasticity $[28,55]$. LTP of synaptic transmission in area CA1 of the hippocampus is dependent on superoxide and is occluded by the superoxide-induced potentiation of synaptic transmission $[28,56]$. NO is known to react with ROS to generate RNS that also cause neuronal cell death through oxidation [32]. Brain injury generates ROS at the early post-traumatic period that spread through the vulnerable central nervous system (CNS) producing the deleterious consequences of brain injuries [31]. It has been shown that melatonin and phenylbutylnitrone, free radical scavengers, had protective effects against TBI via scavenging of ROS and RNS [37-39]. Edaravone is also a free radical scavenger clinically used as a neuroprotective agent against acute cerebral ischemia [33,34]. Edaravone inhibits post-ischemic increases in $\cdot \mathrm{OH}$ production and tissue injury in the penumbral or recirculated area in rat cerebral ischemia models $[35,36]$. 
In addition, it has been reported that edaravone scavenges NO [41]. The present study showed that i.p. administration of edaravone attenuated the FPIinduced enhancement of the fEPSP and the impairment of LTP in dentate granule cell layers. The lack of induction of LTP after brain injury may be due to posttraumatic increase in $\mathrm{NO}$ and/or free radicals, because previous enhancement of these molecules by FPI may suppress any further LTP. Such a pathological enhancement of the function of excitatory synapses would prevent subsequent LTP induction in dentate granule cells. We, therefore, hypothesized that edaravone prevented the pathological form of LTP following brain injury in dentate granule cell layers by suppressing the NO-ROS pathway. The present study examined the effect of sp-NO, a NO donor, on the induction of LTP in brain slice preparations, in vitro. Bath-application of sp-NO $(100 \mu \mathrm{M})$ produced a long-lasting increase in the fEPSP slope in dentate granule cell layers. Such an enhancement of fEPSP slope was blocked by pretreatment with edaravone $(100 \mu \mathrm{M})$. The present study also showed that HFS produced no additional enhancement of the fEPSP in dentate granule cells in the slices pretreated with sp-NO $(100 \mu \mathrm{M})$ alone for $30 \mathrm{~min}$. These results may be due to $\mathrm{NO}$ and/or NO-stimulated free radical production, because application of edaravone attenuated sp-NO-induced enhancement of the fEPSP slope and prevented the impairment of LTP of the fEPSP slope in FPI rats. Although the precise mechanisms of edaravone on the FPI-induced impairment of LTP were not fully elucidated, i.p. administration of edaravone in the early post-traumatic period prevented the impairment of LTP in the rat DG. The results of the present study suggest a therapeutic potential of edaravone against post-traumatic impairment of cognitive functions at brain injury by scavenging $\mathrm{NO}$ and/or free radicals.

ACKNOWLEDGMENTS: The authors are grateful to Mr. G. Wyckoff for reading the manuscript and his useful comments during the present study. This work was partially supported by JSPS KAKENHI, Grant-in-Aid for Scientific Research (C) (17500279 and 20591698). This research was also supported from the Ministry of Education, Culture, Sports, Science and Technology as a part of a project for establishing open research centers in private universities.

\section{REFERENCES}

1. Capruso DX, and Levin HS. Cognitive impairment following closed head injury. Neurol Clin 1992; 10:879-893.

2. Rempel-Clower NL, Zola SM, Squire LR, and Amaral DG. Three cases of enduring memory impairment after bilateral damage limited to the hippocampal formation. J Neurosci
$1996 ; 16: 5233-5255$.

3. Annegers JF, Hauser WA, Coan SP, and Rocca WA. A population-based study of seizures after traumatic brain injuries. N Engl J Med 1998; 338:20-24.

4. Dixon CE, Lyeth BG, Povlishock JT, Findling RL, Hamm RJ et al. A fluid percussion model of experimental brain injury in the rat. J Neurosurg 1987; 67:110-119.

5. McIntosh TK, Vink R, Noble L, Yamakami I, Fernyak S et al. Traumatic brain injury in the rat: characterization of a lateral fluid-percussion model. Neuroscience 1989; 28:233244.

6. Thompson HJ, Lifshitz J, Marklund N, Grady MS, Graham DI et al. Lateral fluid percussion brain injury: a 15-year review and evaluation. J Neurotrauma 2005; 22:42-75.

7. Lowenstein DH, Thomas MJ, Smith DH, and McIntosh TK. Selective vulnerability of dentate hilar neurons following traumatic brain injury: a potential mechanistic link between head trauma and disorders of the hippocampus. $\mathrm{J}$ Neurosci 1992; 12:4846-4853.

8. Toth Z, Hollrigel GS, Gorcs T, and Soltesz I. Instantaneous perturbation of dentate interneuronal networks by a pressure wave-transient delivered to the neocortex. J Neurosci 1997; 17:8106-8117.

9. Coulter DA, Rafiq A, Shumate M, Gong QZ, DeLorenzo RJ et al. Brain injury-induced enhanced limbic epileptogenesis: anatomical and physiological parallels to an animal model of temporal lobe epilepsy. Epilepsy Res 1996; 26:8191.

10. Santhakumar V, Ratzliff ADH, Jeng J, Toth Z, and Soltesz I. Long-term hyperexcitability in the hippocampus after experimental head trauma. Ann Neurol 2001; 50:708-717.

11. Cao R, Hasuo H, Ooba S, Akasu T, and Zhang X. Facilitation of glutamatergic synaptic transmission in hippocampal CA1 area of rats with traumatic brain injury. Neurosci Lett 2006; 401:136-141.

12. Yamashita S, Ooba S, Orito K, Hasuo H, Tokutomi T et al. Edaravone effectively improve the neuronal dysfunction induced by lateral fluid percussion injury in rats. Neurotrauma Res 2006; 18:35-40.

13. Bliss TVP, and Collingridge GL. A synaptic model of memory: long-term potentiation in the hippocampus. Nature 1993; 361:31-39.

14. Lynch MA. Long-term potentiation and memory. Physiol Rev 2004; 84:87-136.

15. Miyazaki S, Katayama Y, Lyeth BG, Jenkins LW, DeWitt DS et al. Enduring suppression of hippocampal long-term potentiation following traumatic brain injury in rat. Brain Res 1992; 585:335-339.

16. Reeves TM, Lyeth BG, and Povlishock JT. Long-term potentiation deficits and excitability changes following traumatic brain injury. Exp Brain Res 1995; 106:248-256.

17. Sick TJ, Pérez-Pinzón MA, and Feng ZZ. Impaired expression of long-term potentiation in hippocampal slices 4 and $48 \mathrm{~h}$ following mild fluid-percussion brain injury in vivo. Brain Res 1998; 785:287-292.

18. D'Ambrosio R, Maris DO, Grady MS, Winn HR, and Janigro D. Selective loss of hippocampal long-term potentiation, but not depression, following fluid percussion injury. Brain Res 1998; 786:64-79.

19. Sanders MJ, Sick TJ, Perez-Pinzon MA, Dietrich WD, and 
Green EJ. Chronic failure in the maintenance of long-term potentiation following fluid percussion injury in the rat. Brain Res 2000; 861:69-76.

20. Atkins CM, Chen S, Alonso OF, Dietrich WD, and Hu BR. Activation of calcium/calmodulin-dependent protein kinases after traumatic brain injury. J Cereb Blood Flow Metab 2006; 26:1507-1518.

21. Schwarzbach E, Bonislawski DP, Xiong G, and Cohen AS. Mechanisms underlying the inability to induce area CA1 LTP in the mouse after traumatic brain injury. Hippocampus 2006; 16:541-550.

22. Schuman EM, and Madison DV. A requirement for the intercellular messenger nitric oxide in long-term potentiation. Science 1991; 254:1503-1506.

23. Meffert MK, Haley JE, Schuman EM, Schulman H, and Madison DV. Inhibition of hippocampal heme oxygenase, nitric oxide synthase, and long-term potentiation by metalloporphyrins. Neuron 1994; 13:1225-1233.

24. Gage AT, Reyes M, and Stanton PK. Nitric-oxide-guanylylcyclase-dependent and -independent components of multiple forms of long-term synaptic depression. Hippocampus 1997; 7:286-295.

25. Dawson VL, Kizushi VM, Huang PL, Snyder SH, and Dawson TM. Resistance to neurotoxicity in cortical cultures from neuronal nitric oxide synthase-deficient mice. J Neurosci 1996; 16:2479-2487.

26. Barth A, Newell DW, Nguyen LB, Winn HR, Wender R et al. Neurotoxicity in organotypic hippocampal slices mediated by adenosine analogues and nitric oxide. Brain Res 1997; 762:79-88.

27. Klann E. Cell-permeable scavengers of superoxide prevent long-term potentiation in hippocampal area CA1. J Neurophysiol 1998; 80:452-457.

28. Knapp LT, and Klann E. Potentiation of hippocampal synaptic transmission by superoxide requires the oxidative activation of protein kinase C. J Neurosci 2002; 22:674-683.

29. Demopoulos HB, Flamm ES, Pietronigro DD, and Seligman ML. The free radical pathology and the microcirculation in the major central nervous system disorders. Acta Physiol Scand Suppl 1980; 492:91-119.

30. Siesjö BK. Cell damage in the brain: a speculative synthesis. J Cereb Blood Flow Metab 1981; 1:155-185.

31. Lewén A, Matz P, and Chan PH. Free radical pathways in CNS injury. J Neurotrauma 2000; 17:871-890.

32. Pannu R, and Singh I. Pharmacological strategies for the regulation of inducible nitric oxide synthase: neurodegenerative versus neuroprotective mechanisms. Neurochem Int 2006; 49:170-182.

33. Otani H, Togashi H, Jesmin S, Sakuma I, Yamaguchi T et al. Temporal effects of edaravone, a free radical scavenger, on transient ischemia-induced neuronal dysfunction in the rat hippocampus. Eur J Pharmacol 2005; 512:129-137.

34. Yoshida H, Yanai H, Namiki Y, Fukatsu-Sasaki K, Furutani $\mathrm{N}$ et al. Neuroprotective effects of edaravone: a novel free radical scavenger in cerebrovascular injury. CNS Drug Rev 2006; 12:9-20.

35. Watanabe T, Yuki S, Egawa M, and Nishi H. Protective effects of MCI-186 on cerebral ischemia: possible involvement of free radical scavenging and antioxidant actions. J Pharmacol Exp Ther 1994; 268:1597-1604.
36. Yamamoto T, Yuki S, Watanabe T, Mitsuka M, Saito KI et al. Delayed neuronal death prevented by inhibition of increased hydroxyl radical formation in a transient cerebral ischemia. Brain Res 1997; 762:240-242.

37. Marklund N, Clausen F, McIntosh TK, and Hillered L. Free radical scavenger posttreatment improves functional and morphological outcome after fluid percussion injury in the rat. J Neurotrauma 2001; 18:821-832.

38. Samuelsson C, Kumlien E, Elfving A, Lindholm D, and Ronne-Engström E. The effects of PBN (phenyl-butylnitrone) on GLT-1 levels and on the extracellular levels of amino acids and energy metabolites in a model of ironinduced posttraumatic epilepsy. Epilepsy Res 2003; 56:165173.

39. Ozdemir D, Tugyan K, Uysal N, Sonmez U, Sonmez A et al. Protective effect of melatonin against head traumainduced hippocampal damage and spatial memory deficits in immature rats. Neurosci Lett 2005; 385:234-239.

40. Ooba S, Hasuo H, Shigemori M, and Akasu T. Diazepam attenuates the post-traumatic hyperactivity of excitatory synapses in rat hippocampal CA1 neurons. Neurosci Res 2008; 62:195-205.

41. Satoh K, Ikeda Y, Shioda, S, Tobe T, and Yoshikawa T. Edaravone scavenges nitric oxide. Redox Rep 2002; 7:219222.

42. Santhakumar V, Bender R, Frotscher M, Ross ST, Hollrigel GS et al. Granule cell hyperexcitability in the early posttraumatic rat dentate gyrus: the 'irritable mossy cell' hypothesis. J Physiol 2000; 524:117-134.

43. Sloviter RS. Permanently altered hippocampal structure, excitability, and inhibition after experimental status epilepticus in the rat: the "dormant basket cell" hypothesis and its possible relevance to temporal lobe epilepsy. Hippocampus 1991; 1:41-66

44. Sloviter RS. On the relationship between neuropathology and pathophysiology in the epileptic hippocampus of humans and experimental animals. Hippocampus 1994; 4:250-253.

45. Babb TL. Axonal growth and neosynaptogenesis in human and experimental hippocampal epilepsy. Adv Neurol 1997; 72:45-51

46. Frotscher M, and Zimmer J. Lesion-induced mossy fibers to the molecular layer of the rat fascia dentata: identification of postsynaptic granule cells by the Golgi-EM technique. J Comp Neurol 1983; 215:299-311.

47. Sutula T, He XX, Cavazos J, and Scott G. Synaptic reorganization in the hippocampus induced by abnormal functional activity. Science 1988; 239:1147-1150.

48. Bliss TVP, and Lømo T. Long-lasting potentiation of synaptic transmission in the dentate area of the anaesthetized rabbit following stimulation of the perforant path. J Physiol 1973; 232:331-356.

49. Obrenovitch TP, and Urenjak J. Altered glutamatergic transmission in neurological disorders: from high extracellular glutamate to excessive synaptic efficacy. Prog Neurobiol 1997; 51:39-87.

50. Faden AI, Demediuk P, Panter SS, and Vink R. The role of excitatory amino acids and NMDA receptors in traumatic brain injury. Science 1989; 244:798-800.

51. Katayama Y, Becker DP, Tamura T, and Hovda DA. Massive increases in extracellular potassium and the indiscriminate 
release of glutamate following concussive brain injury. J Neurosurg 1990; 73:889-900.

52. Hayes RL, Jenkins LW, and Lyeth BG. Neurotransmittermediated mechanisms of traumatic brain injury: acetylcholine and excitatory amino acids. J Neurotrauma 1992; 9:S173-S187.

53. Nowak L, Bregestovski P, Ascher P, Herbet A, and Prochiantz A. Magnesium gates glutamate-activated channels in mouse central neurones. Nature 1984; 307:462-465.

54. Zhang L, Rzigalinski BA, Ellis EF, and Satin LS. Reduction of voltage-dependent $\mathrm{Mg}^{2+}$ blockade of NMDA current in mechanically injured neurons. Science 1996; 274:19211923.

55. Thiels E, Urban NN, Gonzalez-Burgos GR, Kanterewicz $\mathrm{BI}$, Barrionuevo $\mathrm{G}$ et al. Impairment of long-term potentiation and associative memory in mice that overexpress extracellular superoxide dismutase. J Neurosci 2000; 20:7631-7639.

56. Klann E, Roberson ED, Knapp LT, and Sweatt JD. A role for superoxide in protein kinase $\mathrm{C}$ activation and induction of long-term potentiation. J Biol Chem 1998; 273:45164522 . 